\title{
Marianne KRÖGER, «Jüdische Ethik» und Anarchismus im Spanischen Bürgerkrieg
}

Frankfurt am Main, Verlag Peter Lang, 2009, 204 p.

\section{Michael Löwy}

\section{CpenEdition} Journals

Édition électronique

URL : http://journals.openedition.org/assr/22042

DOI : $10.4000 /$ assr.22042

ISSN : 1777-5825

Éditeur

Éditions de l'EHESS

Édition imprimée

Date de publication : 31 décembre 2010

Pagination : 9-242

ISBN : 9782713223013

ISSN : 0335-5985

Référence électronique

Michael Löwy, « Marianne KRöGER, «Jüdische Ethik» und Anarchismus im Spanischen Bürgerkrieg », Archives de sciences sociales des religions [En ligne], 152 I octobre-décembre 2010, document 152-70, mis en ligne le 12 mai 2011, consulté le 21 septembre 2020. URL : http://journals.openedition.org/ assr/22042 ; DOI : https://doi.org/10.4000/assr.22042

Ce document a été généré automatiquement le 21 septembre 2020.

(C) Archives de sciences sociales des religions 


\title{
Marianne KRÖGER, «Jüdische Ethik» und Anarchismus im Spanischen Bürgerkrieg
}

Frankfurt am Main, Verlag Peter Lang, 2009, 204 p.

\author{
Michael Löwy
}

\section{RÉFÉRENCE}

Marianne KRÖGER, «Jüdische Ethik» und Anarchismus im Spanischen Bürgerkrieg, Frankfurt am Main, Verlag Peter Lang, 2009, 204 p., Frankfurt am Main, Verlag Peter Lang, 2009, $204 \mathrm{p}$.

1 Il s'agit d'une étude sur trois intellectuels juifs qui se sont engagés activement dans le combat du mouvement anarcho-syndicaliste - la CNT-FAI (Confédération Nationale du Travail - Fédération anarchiste ibérique) - pendant la guerre civile en Espagne (1936-39): Simone Weil, Carl Einstein, Etta Federn. La première, philosophe sociale française, participera, pour quelques jours seulement, aux combats de la colonne dirigée par le célèbre militant anarchiste Buenaventura Durruti; l'engagement du deuxième, historien d'art allemand exilé en France, dans les rangs de la même colonne, et plus tard dans l'armée républicaine, s'étendra pendant les trois années de la guerre civile; la troisième, écrivaine autrichienne, établie en Espagne dès 1932, deviendra une des animatrices du mouvement de femmes anarchistes Mujeres Libres. Après la défaite de la République espagnole, Carl Einstein et Etta Federn reviendront en France; le premier va se suicider au début de l'occupation (1940) et la seconde s'engagera dans la Résistance à Lyon.

Dans quelle mesure l'engagement libertaire de ces trois personnages, de culture universaliste et cosmopolite, sans liens profonds avec la religion ou la culture juive, relève-t-il d'une «éthique juive»? L'hypothèse avancée par l'auteure est que les valeurs éthiques de justice, inhérentes au judaïsme, ont été sécularisées par ces penseurs sous 
une forme humaniste/ universaliste: le combat anarchiste pour l'égalité et la justice sociale. L'hypothèse est intéressante, mais les éléments que le livre apporte, sur le rapport, distant et peu contraignant, de ces trois figures au judaïsme ne permettent pas de la confirmer. D'autant plus que tous les trois vont se rapprocher, vers la fin de leur vie, du christianisme, envisageant même une conversion au catholicisme (Simone Weil et Carl Einstein) ou au protestantisme (Etta Federn). Tous trois semblent convaincus de la supériorité du christianisme, comme religion universelle, sur le judaïsme, perçu comme trop particulariste.

3 Ce qui manque à cet ouvrage, par ailleurs intéressant, est une comparaison avec les penseurs juifs/allemands dont l'attirance pour le messianisme juif semble directement inspirer leur sympathie pour l'utopie libertaire: Gustav Landauer, Martin Buber, Gershom Scholem, Walter Benjamin, parmi d'autres. 